\title{
The offset effect of pharmaceutical innovation: A review study
}

Global \& Regional Health Technology

Assessment

Volume 2019: 1-10

(C) The Author(s) 2019

Article reuse guidelines:

sagepub.com/journals-permissions DOI: 10.1 I77/2284240319875।08

journals.sagepub.com/home/grh

(3)SAGE

\author{
Néboa Zozaya',2 (D), Bleric Alcalá' and Jhon Galindo'
}

\begin{abstract}
It is well known that pharmaceutical innovation has improved the health and quality of life of patients. It is however sometimes forgotten that new drugs also have the potential of improving the efficiency and the sustainability of the healthcare system. The objective of this review is to shed light on the magnitude of the offset effect that drugs may have in the realm of the healthcare system and for society as a whole. A narrative literature review was carried out. This review demonstrated that a growing body of literature has tried to measure the magnitude of the offset effect associated with pharmaceutical innovation, both at the aggregate level and for different diseases. There is evidence that the aggregate use of new drugs can generate net savings to the healthcare system and to society, as they may release both healthcare and non-healthcare resources for alternative uses. A high degree of heterogeneity in the magnitude of the effect has been found across different pathologies and different types of drugs.
\end{abstract}

\section{Keywords}

Pharmaceutical innovation, drugs, offset effect, savings, costs, economic impact

Date received: 13 May 2019; accepted: 9 August 2019

\section{Introduction}

Pharmaceutical innovation (PI) has contributed to substantial improvements in the health and quality of life of people in modern societies. Indeed, drug innovation has not only allowed for the cure and the prevention of diseases but has also helped to reduce symptoms, increase life expectancy, accelerate recovery time, reduce adverse effects and negative interaction with other drugs, and find new routes of administration that are more comfortable for the patient. ${ }^{1}$

PI implies a complex scientific and technological process associated with long research periods and high financial investment. It is estimated that developing a new molecule may cost up to USD 2700 million and take up to 15 years of research. ${ }^{2}$ Nevertheless, despite the cost that PI may represent to healthcare systems, an offset effect is often produced on other costs, which may lead to significant global savings in the total costs associated with the new drug's introduction to the market.

Hence, beyond their clinical impact, drugs often have additional benefits on the healthcare system and society in general. Indeed, by preventing or treating more effectively different illnesses, PI, as many healthcare interventions, may reduce several direct and indirect costs associated with the disease and therefore become a very useful tool for optimal resource utilization. ${ }^{3}$

In the health economics literature, direct costs refer to both direct healthcare costs (DHC) and direct nonhealthcare costs (DNHC). The former refers to the use of resources that is strictly related to illness management,

'Department of Health Economics, Weber, Madrid, Spain

2University of Las Palmas de Gran Canaria, Las Palmas, Spain

Corresponding author:

Néboa Zozaya, Department of Health Economics, Weber, c/ Moreto 17, 28014 Madrid, Spain.

Email: neboa.zozaya@weber.org.es 
such as medication costs, medical visits, hospitalizations and laboratory tests. The latter refers, among other costs, to the value of the care that the patient receives at home, in the form of formal caregiving (i.e. when care is provided by paid professionals) or of informal caregiving (i.e. when care is provided by relatives and friends). Indirect costs are defined as those that include permanent and temporary labour productivity losses caused by the illness, which represent a loss of wealth for society.

The objective of this study is to shed light on the potential that drugs have to generate savings for the healthcare system and for society in general. Throughout the article, we provide different illustrative examples, both in concrete therapeutic areas and in general, that were found through a narrative literature review.

\section{Methods}

A narrative literature review was carried out using Medline (PubMed) and Google Scholar. The search included fulltext articles and documents published until September 2017 that analysed or measured the offset effect of drugs. Only documents written in English or Spanish were included. The search terms used included 'offset effect', 'savings', 'costs', 'productivity' and 'drugs'. References of the included studies were also examined. The search was complemented with grey literature and documents of relevant organizations, such as government departments.

\section{Results}

\section{Savings in DHC}

By improving the patients' health status, the use of new drugs is often translated into a decrease in the utilization of healthcare resources, such as hospitalizations, medical visits, and concomitant medication, leading to financial savings, or releasing resources for other uses within the healthcare system. A growing body of literature has tried to measure the magnitude of this offset effect that is associated with PI, both at the aggregate level and for different concrete pathologies.

Lichtenberg was one of the first authors who quantified the offset effect of drugs at the general level, leading to the notion that PI's economic and social contribution could significantly exceed its costs. In a study published in 2001 , the author estimated that if a 15-year-old drug was to be replaced by a 5.5 -year-old one, per capita pharmaceutical expenditure in the United States would increase by USD 18 on average, while non-pharmaceutical expenditure would decrease by USD 72, leading to a savings ratio of almost 4 times the cost of the introduction of the newest drug. ${ }^{4} \mathrm{He}$ later updated his analysis for the years 1997 and 1998 and obtained a savings ratio of 7.2 in the entire population and 8.3 for the population covered by Medicare, basically due to savings in hospitalizations. ${ }^{5}$ In another study, Lichtenberg ${ }^{6}$ estimated that, even under a most conservative cost methodology, the net cost of new drugs was negative, as they would generate savings in hospitalization and nursing home costs equivalent to 2.4 times the cost of the drugs.

Other authors later found that the magnitude of the aggregate offset effect of new drugs in the United States actually amounted to intermediate values. For example, Civan and Koksal focused on Medicare- and Medicaidcovered population and obtained a net per capita savings ratio of 5.5 when using newer drugs (actually, when the average age of the drug being assessed was reduced in 1 year). However, the authors also found significant heterogeneity among different drug classes. ${ }^{7}$ In another study, Santerre (2011) obtained estimations for the United States and six other Organisation for Economic Co-operation and Development (OECD) countries and found larger offset effects in the long run than in the short run. Indeed, according to the author, the marginal effect of commercializing a new medication was equivalent to net per capita savings in healthcare costs of USD 5.9 in the short run and USD 11.4 in the long run. These findings implied aggregated savings at the national level of USD 1800 million and USD 3400 million in the short and long run, respectively. ${ }^{8}$

Public organizations like the Congressional Budget Office have also validated the offset effect of PI in the United States. Their study highlighted that, in the case of the Medicare-covered population, a $1 \%$ increase in the number of annual prescriptions translated into a $0.2 \%$ decrease in annual healthcare costs. ${ }^{9}$ Based on this finding and on the volume of prescriptions filled in 2014, Lakdawalla et al. ${ }^{10}$ estimated that each additional prescription led to savings of USD 94 in DHC in that same year.

The existence of an offset effect associated with PI has also been confirmed in other countries. For example, in Canada, Crémieux et al. ${ }^{11}$ estimated that each additional dollar invested in new drugs yields an average reduction of CAD 4.7 in hospital expenditure and of CAD 1.5 in global healthcare expenditures. In Spain, an increase of $10 \%$ in hospital drugs expenditure between 1995 and 2005 led to net per capita savings of EUR 1.1 in total hospital expenditures. ${ }^{12}$

\section{Savings by therapeutic area}

Many studies have analysed the economic impact that drugs have in specific therapeutic areas, finding that in those cases, PI also often translates into net savings in costs. In what follows, we summarize some examples found in the literature.

In the oncology area, drugs that were commercialized between 1980 and 1997 in Canada avoided 1.7 million 
hospitalization days per year, which translated into savings that approximated CAD 4700 million (base year 2012), a significantly higher amount than the annual expenditure in cancer drugs in that country. ${ }^{13}$ Likewise, in the United States, a study estimated that cancer treatments launched between 1989 and 2005 avoided 1.55 million hospitalization days in 2013, thereby reducing hospitalization costs by USD 4800 million in that same year. ${ }^{14}$ There is also evidence that oncological PI increased healthcare cost savings in Australia. ${ }^{15}$

Multiple examples of offset effects have also been found in the cardiovascular area. In OECD countries, pharmaceutical expenditure in cardiovascular illnesses increased by USD 24 per capita between 1995 and 2004, which in turn led to estimated hospitalization savings of USD 89 per capita. ${ }^{16}$ A study by the British National Health Service estimated that treating atrial fibrillation patients with anticoagulant therapy was associated with net per capita savings of GBP 412 in the short run and GBP 2408 throughout the patient's lifetime. This same study found additional savings for society of GBP 94 and GBP 1379 in the short and long run, respectively. ${ }^{17}$ Likewise, according to a clinical trial conducted in the United States, the use of statins has led to a $27 \%$ reduction in other healthcare costs related to illness management, thereby allowing for an $11 \%$ reduction in total cardiovascular healthcare costs. ${ }^{18}$ Another study found that the use of antihypertensive medication was associated with a benefit-cost ratio of $6: 1$ in women and of 10:1 in men. ${ }^{19}$

Other examples can be found for other illnesses, such as depression, asthma and HIV/AIDS. In the United States, the total net healthcare cost per patient diagnosed with depression was reduced during the 1990 s by $18 \%$, mainly due to the decrease in hospitalization costs that was produced by innovations in drug treatment. ${ }^{20}$ In Ireland, the use of new monoclonal antibodies in asthmatic patients led to a reduction in exacerbations and allowed for a decrease of $14.5 \%$ in net DHC. ${ }^{21}$ Finally, studies have demonstrated that while the use of antiretroviral therapy has increased drug expenditure in patients with HIV/ AIDS, it has also decreased other healthcare costs, leading to net savings of $10 \% .^{22}$

The power of vaccines. Vaccines are one of the most costeffective public health interventions. ${ }^{23}$ Their economic value has been studied from different angles, ${ }^{24-26}$ with benefits that can be measured in terms of decreases in morbidity and mortality rates, savings for the healthcare system, gains in labour productivity and positive externalities in both the short and the long run. ${ }^{27}$

Traditional vaccines have generated important net savings for the healthcare system and for society. The eradication of smallpox is associated with savings in global costs of over USD 2000 million per year. ${ }^{23}$ The net benefit of the polio vaccine in the United States has reached over 6 times its cost. ${ }^{28}$ According to another study, each dollar invested in the United States in nine types of children vaccines led to savings of USD 13 in the short run, of which USD 10 corresponded to indirect costs. ${ }^{25}$ In the long run, savings in social costs associated with vaccines for children could reach USD 27 for each dollar invested, of which USD 9 would correspond to savings for the healthcare system. ${ }^{26}$ It has been estimated that, in low- and middle-income countries, children vaccination programmes generate a return of 44 times their cost (uncertainty range: 27-67) if all social and economic benefits in the long run are taken into account. ${ }^{24}$

Influenza vaccines have proved to be an efficient health intervention, especially in high-risk populations, such as the elderly, whose vaccination could avoid up to $39 \%$ of influenza- and pneumonia-related hospitalizations, ${ }^{29}$ leading in turn to a benefit-cost ratio of over 1 in countries such as England and Wales. ${ }^{30} \mathrm{~A}$ recent systematic review concluded that these vaccines were generally a costeffective option in the European Union. ${ }^{31}$

The newest vaccines, such as those to prevent hepatitis and the human papilloma virus, came out of more complex research processes and are therefore more costly than older vaccines. However, they still have proved to be costeffective under a EUR 30,000 per quality-adjusted lifeyear cost-effectiveness threshold. ${ }^{32}$

Adherence to treatment as a cost savings driver. A determinant driver for cost savings is the degree of adherence to treatment, as it does not only favour the treatment's success but it also reduces the risk of the patient suffering a relapse. The highest the degree of adherence to treatment, the higher the drug costs associated with it but the lower the total healthcare costs associated with medical visits, hospitalizations and emergency admissions. ${ }^{33}$

According to a recent systematic review that was carried out on 14 groups of illnesses, the economic cost of the lack of adherence to treatment ranged between USD 949 and USD 44,190 per year in the United States. ${ }^{34}$ Another study found that each dollar invested in improving adherence to treatment led to net average savings in healthcare costs equivalent to USD 7.1 in diabetes, USD 5.1 in hypercholesterolemia and USD 4 in hypertension. According to this same study, a patient with high adherence level $(80 \%-100 \%)$ would save the healthcare system an average of $29 \%$ of the costs in hypercholesterolemia, $27 \%$ in diabetes, $9 \%$ in heart failure and $7 \%$ in hypertension, compared to a patient with a medium adherence level $(60 \%-79 \%)^{35}$ (Figure 1). Yet, another study carried out in the United States has estimated that a higher adherence to treatment in the case 


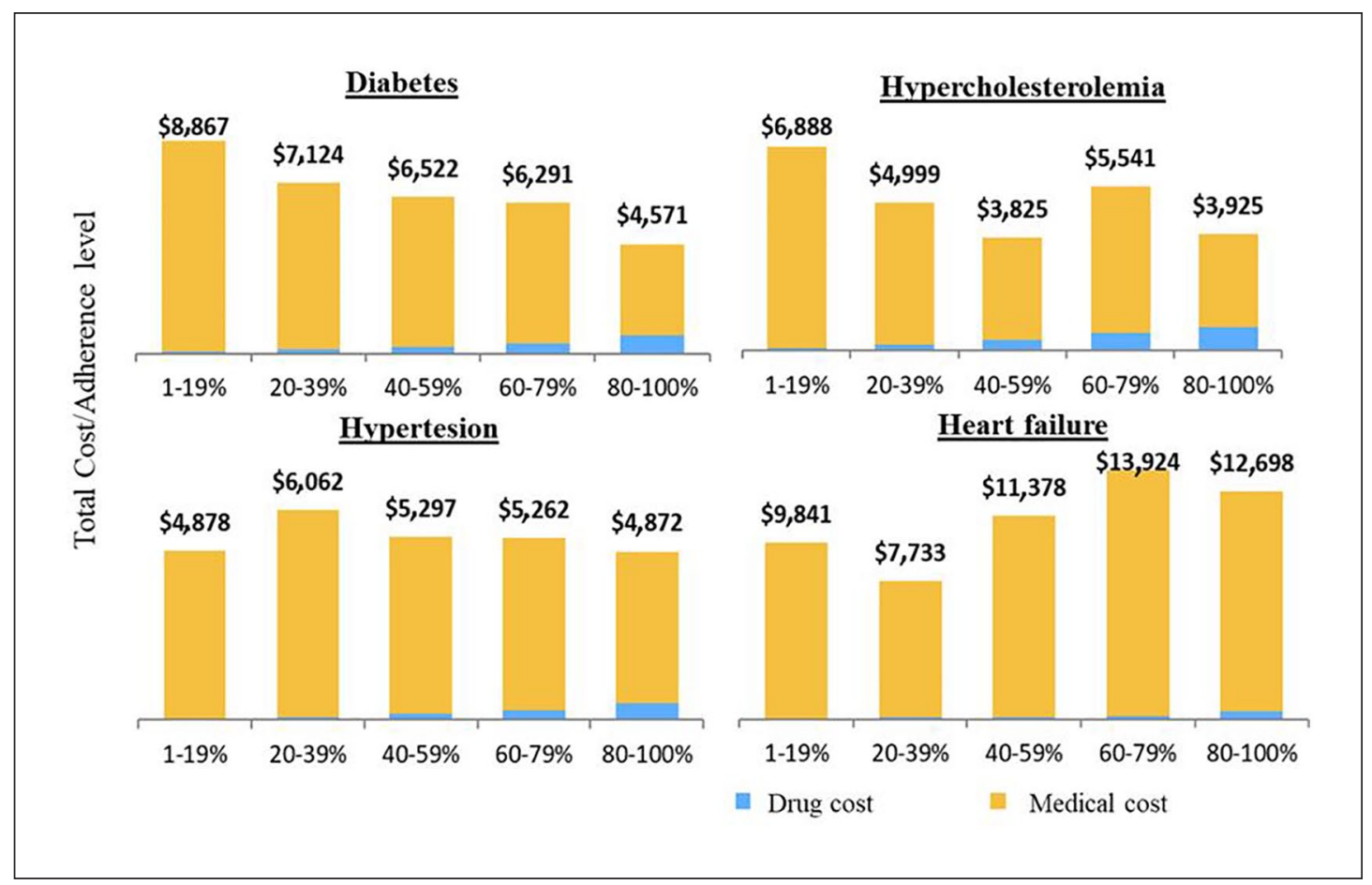

Figure I. Costs related to four chronic illnesses, by degree of patients' adherence (\%), the United States 1997-1999. Source: Generated by the authors based on Sokol et al. ${ }^{35}$

This figure was created by Microsoft Office Excel.

of chronic illnesses like chronic obstructive pulmonary disease (COPD), diabetes and heart failure would reduce Medicare costs between $29 \%$ and $49 \%{ }^{36}$

In diabetes, in the context of an integrated disease management programme, a reduction from $8.2 \%$ to $7.7 \%$ in glycosylated haemoglobin has been associated with a $22 \%$ decrease in hospital admissions and a $34 \%$ decrease in the patient's average length of stay. ${ }^{37}$ Other studies also confirmed that changes in the insulin administration route led to a higher adherence level, reduced hypoglycaemias and generated savings in the average DHC per patient. ${ }^{38,39}$

\section{Savings in DNHC}

As a consequence of illness, many patients have limited autonomy and therefore need personal caregivers, who may either be formal caregivers (professional health workers) or informal caregivers (family or friends). Medication may reduce many limitations patients have when performing daily activities and thereby reduce the amount of personal care they need. Even though literature on the economic impact that drugs may have on caregiving costs is scarce, some studies have been published on this topic.

Regarding informal care, a meta-analysis concluded that medical treatment for dementia reduced both the care burden (with a 0.27 difference in the care burden questionnaire) and the time dedicated to caregiving (a reduction between 25 and 58 minutes per day)..$^{40}$ In psoriasis, new biologic medications reduced the average burden of care at home from 28 to 10 days in Italy, which in turn reduced missed days at work of caregivers from 8 to 2 days per year. ${ }^{41}$

In addition to easing the burden on caregivers, medications may promote efficiency and sustainability within the healthcare system by freeing up resources for other activities. For example, according to a Dutch study that analysed the effect on comprehensive care to patients in a group of 10 PIs that were commercialized between 1995 and 2007, these new drugs represented annual savings that were equivalent to employing 7200 healthcare professionals. ${ }^{42}$

\section{Improvements in labour productivity}

Clinical advancements produced by PI may in turn improve the patient's work capacity, which could be directly translated into a lower degree of absenteeism and presenteeism in the labour market. Thus, at the aggregate level, new medicines may contribute to the economic prosperity of a country by increasing its labour supply, the number of hours worked per person and the average productivity per hour, which will result in an improvement in total labour productivity for the whole society.

In Germany, it has been estimated that each new drug has avoided on average around 200 annual years of lost labour productivity due to early retirement and premature mortality. The cumulative gain in this country, in terms of 
years of work produced between 1988 and 2004 thanks to new medicines, is estimated at around $10 \%$ of the labour loss for the year 2004.43

In some of his studies, Lichtenberg analysed the impact of PI on productivity. He estimated that each additional year of novelty of a drug would lead to a $1 \%$ savings in labour productivity losses. Also, according to the author's findings, reducing labour losses in 1 day would require an average cost in medicines of between USD 18 and USD 34 . This is at least 4 times lower than the average daily wage in the United States (USD 140), which suggests that this investment in drugs would be convenient for society. ${ }^{44}$ In a later study, Lichtenberg estimated the stock value of new drugs in terms of the increase they brought in labour productivity in between 2.3 and 8.1 times the investment they represented. ${ }^{45}$

A large amount of the studies in this field focus on specific pathologies. For example, it has been estimated that each dollar invested in medical treatment for depression in the Unites States during the 1990s decade spared USD 0.56 in labour productivity losses..$^{20}$ In Italy, among patients with moderate or severe psoriasis, biologic therapies have allowed a reduction of $71.4 \%$ in indirect costs associated with the disease.$^{41}$ In Germany, new drugs against rheumatoid arthritis have allowed indirect costs to decrease in $8 \%$ (from EUR 10,609 per patient in the year 2000 to EUR 9754 per patient in 2012) ${ }^{46}$

Adherence to treatment also improves productivity. For instance, adherent workers with diabetes, hypertension, dyslipidaemia, asthma or COPD reduced their absenteeism between 1.7 and 7.1 days per year and had work leaves between 1.1 and 5 days shorter than non-adherent workers. ${ }^{47}$ Annual savings in indirect costs associated with adherence to treatments for asthma and COPD approximate USD 1700 per worker in the United States. In Spain, labour productivity losses significantly decrease when asthma/COPD is adequately controlled (from $22 \%$ of total costs when not controlled to $2.6 \%$ when adequately controlled). ${ }^{48}$

\section{Discussions and conclusions}

This narrative review of the literature has shed light on the value of PI. New drugs may not only improve population's health but also improve efficiency and sustainability within the healthcare system and society as a whole.

A string of literature indicates the existence of an offset effect of PI and suggests that investment in drugs often releases both healthcare and non-healthcare resources for alternative uses. When this is the case, allocation of resources in drugs procurement can be considered as an investment rather than expenditure. As stated before, numerous examples prove that new drugs can not only be cost-effective but can also generate net savings (Table 1).

Lichtenberg was one of the first and most proliferous authors in this field. However, myriad other authors have subsequently refined and clarified initial findings. In general, published studies have used two different approaches to analyse offset effects: the aggregate level and the disease level. Both approaches have found significant offset effects of PI, even if a high degree of heterogeneity in the magnitude of the effect has been found across different pathologies and different types of drugs. ${ }^{7}$ Most studies focused on the United States, where the offset effect of drugs has helped to design changes in Medicare's coverage policies.

The appropriateness of the methodology used to reach any study's results and conclusions is of the highest importance. There is a string of literature that questions the methods and the evidence used when eliciting published results. These authors sustain that the use of new drugs does not necessarily decrease the demand for other types of healthcare. Thus, at least in the short run, PI would lead to an increase in total healthcare costs. ${ }^{49-55}$ The way in which novelty, savings and costs are measured may have a profound impact on final results. One should also be aware of possible publication bias in one or the other direction.

The review has several limitations. The first one is that it is a narrative review that is aimed at providing a broad overview of the studied domain. It does not differentiate between different types of medicines and populations. It does not always distinguish existing medicines from latest generation products, neither their mode of use. The second limitation is that, it does not judge the methodological quality of the scientific evidence of studies. Finally, a common limitation of many included studies is the inability to establish a causal link between medication adherence and total healthcare costs.

In any case, it seems clear that there is a growing tendency to try to associate investment in PIs with the value they bring to society. Value-based approaches are increasingly being used in decision-making processes in many developed countries that are implementing reforms to promote efficiency and sustainability within their healthcare systems. ${ }^{56}$ Value-based prices will depend not only on those health and quality-of-life outcomes attributable to the new drug but also on the savings it may generate, and on society's willingness to pay for the new drug's marginal increase in health compared to that of its comparator..$^{57}$

Indeed, countries such as Australia, England and Sweden take into account evidence related to drugs' offset effect in order to decide whether to allow a price premium or not when it comes to a new drug for a particular illness, including evidence on potential savings that may arise in non-healthcare services. ${ }^{49,58}$ Nevertheless, in many countries, the possibility that the consumption of new drugs may generate nonpharmaceutical healthcare costs or savings either in the very short run or in the medium long run seems to be a missing consideration in deliberations regarding drug price control policy deliberation. 


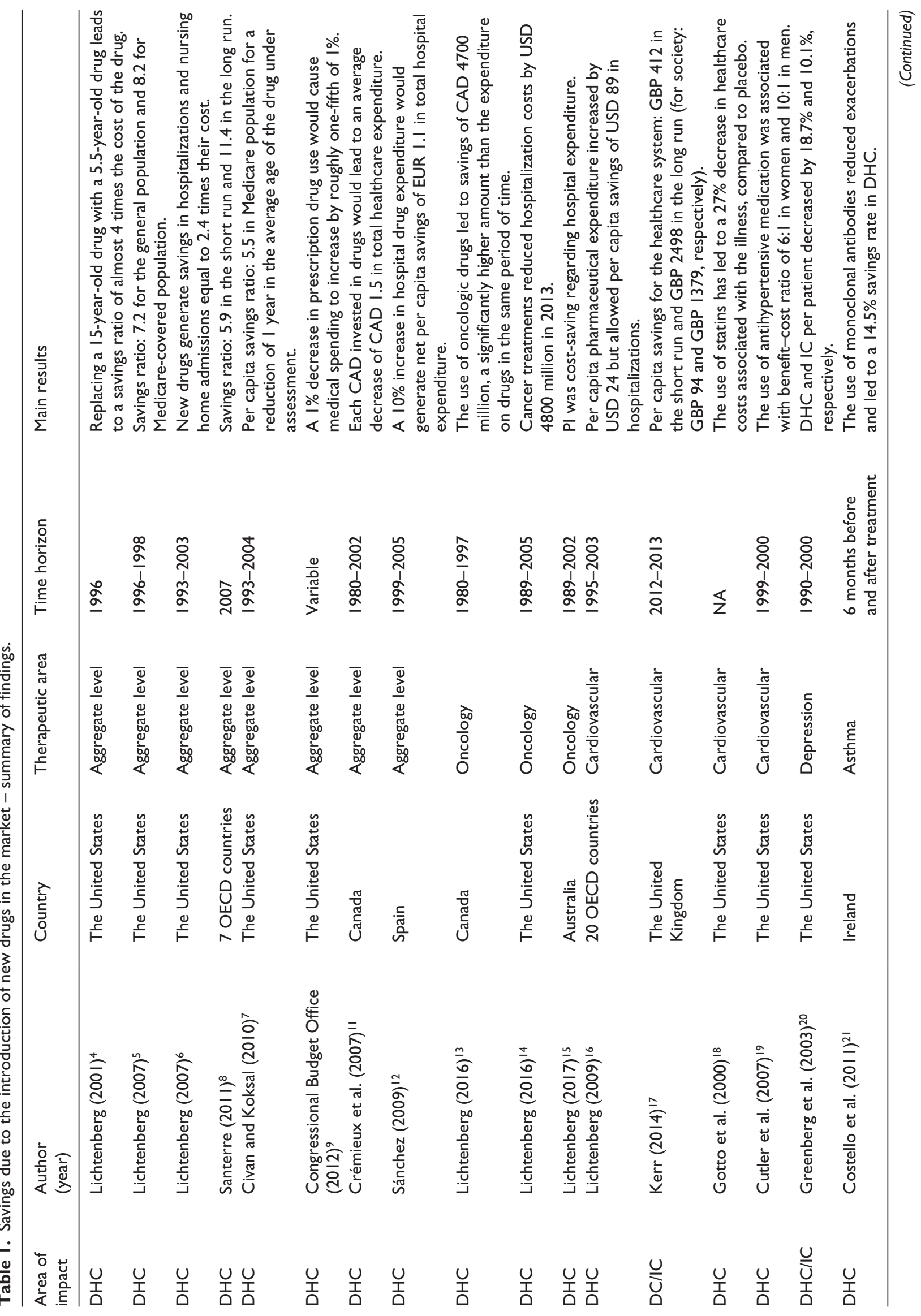




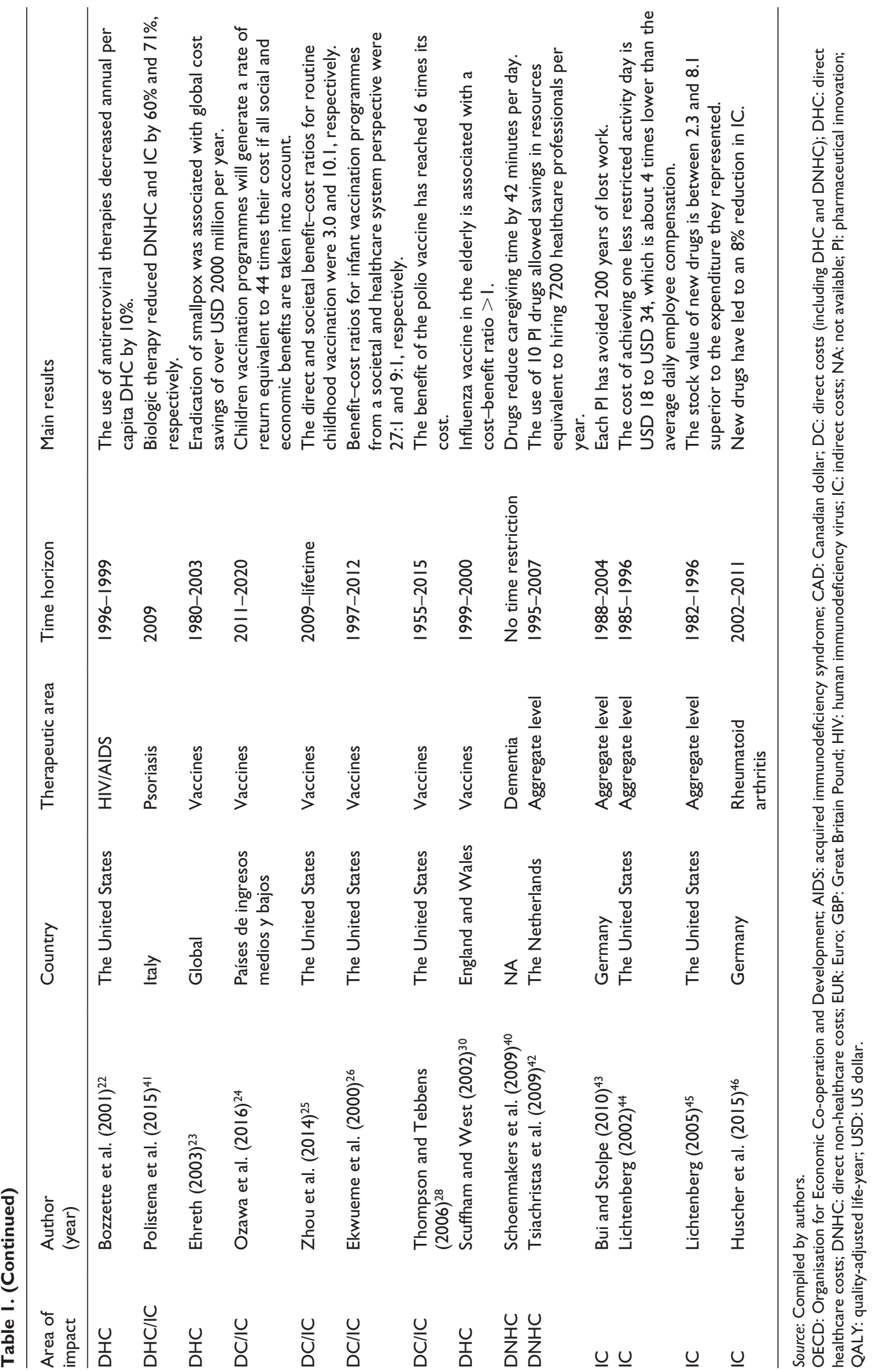


Given that the offset effect has important healthcare policy implications, gathering robust evidence is critical. Decision-makers need more rigorous longitudinal studies to assess whether different drug groups or specific drugs improve health results and decrease global costs. Evidence must consider all possible cost spectrum, including not only DHC but also possible impacts on caregiving burden and labour productivity. Time is also an important factor, that is, addressing whether the use of a given medication precedes, is contemporaneous with, or follows non-drug healthcare costs in a given year.

In conclusion, in order to assess the real social value of new drugs, researchers should consider not only their cost but also their potential offset effect in terms of savings to the healthcare system and to society as a whole. Further subgroup analyses are needed to endorse current published results. However, there is enough evidence that sustains the notion that PI often contributes to society not only in terms of clinical benefits but also in terms of efficiency and sustainability.

\section{Data availability}

The datasets analysed during the current study are available from the corresponding author on reasonable request.

\section{Research involving human participants and/or animals}

This article does not contain any studies with human participants or animals performed by any of the authors.

\section{Declaration of conflicting interests}

The author(s) declared no potential conflicts of interest with respect to the research, authorship and/or publication of this article.

\section{Funding}

The author(s) disclosed receipt of the following financial support for the research, authorship and/or publication of this article: This study was funded by Farmaindustria (the National Trade Association of the Spanish-based pharmaceutical industry), although Farmaindustria did not influence the results of the study.

\section{ORCID iD}

Néboa Zozaya (iD) https://orcid.org/0000-0003-4618-6894

\section{References}

1. Weber. Informe El Valor del Medicamento desde una Perspectiva Social, http://weber.org.es/publicacion/ elvalordelmedicamentodesdeunaperspectivasocial/ (2018, accessed 5 December 2018).

2. DiMasi JA, Grabowski HG and Hansen RW. Innovation in the pharmaceutical industry: new estimates of R\&D costs. $J$ Health Econ 2016; 47: 20-33.

3. Wyden R and Harkin T. Health prevention: cost-effective services in recent peer-reviewed health care literature. U.S. Government Accountability Office, https://www.gao.gov/ assets/670/665276.pdf (2014, accessed 16 August 2018).
4. Lichtenberg FR. Are the benefits of newer drugs worth their cost? Evidence from the 1996 MEPS. Health Aff 2001; 20(5): 241-251.

5. Lichtenberg FR. Benefits and costs of newer drugs: an update. Manag Decis Econ 2007; 28: 485-490.

6. Lichtenberg FR. The impact of new drugs on US longevity and medical expenditure, 1990-2003: evidence from longitudinal, disease-level data. Am Econ Rev 2007; 97: 438-443.

7. Civan A and Koksal B. The effect of newer drugs on health spending: do they really increase the costs? Health Econ 2010; 19(5): 581-595.

8. Santerre RE. National and international tests of the new drug cost offset theory. South Econ J 2011; 77: 10331043.

9. Congressional Budget Office. Offsetting effects of prescription drug use on Medicare's spending for other medical services, http://www.cbo.gov/sites/default/files /43741-MedicalOffsets-11-29-12.pdf (2012, accessed 30 July 2018).

10. Lakdawalla D, MacEwan JP, Dubois R, et al. What do pharmaceuticals really cost in the long run? Am J Manag Care 2017; 23: 488-493.

11. Crémieux PY, Ouellette P and Petit P. Do drugs reduce utilisation of other healthcare resources? Pharmaco Economics 2007; 25(3): 209-221.

12. Sánchez PL. Gasto en medicamentos innovadores y sostenibilidad. VII Seminario Industria Farmacéutica y Medios de Comunicación. Farmaindustria, http://www.farmaindustria. es/idc/groups/public/documents/otrosdocumentos/ farma_100368.pdf (2009, accessed 2 October 2018).

13. Lichtenberg FR. The benefits of pharmaceutical innovation: health, longevity, and savings. Montreal Economic Institute, https://www.iedm.org/files/cahier0216_en.pdf(2016, accessed 5 December 2018).

14. Lichtenberg FR. How cost-effective are new cancer drugs in the U.S.? CESifo working paper series no. 6683, https://www.cesifo-group.de/dms/ifodoc/docs/ Akad_Conf/CFP_CONF/CFP_CONF_2017/am17Gollier/Papers/am17_Lichtenberg.pdf (2016, accessed 5 December 2018).

15. Lichtenberg FR. The impact of pharmaceutical innovation on premature mortality, hospital separations, and cancer survival in Australia. Econ Record 2017; 93: 353-378.

16. Lichtenberg FR. Have newer cardiovascular drugs reduced hospitalization? Evidence from longitudinal country-level data on 20 OECD countries, 1995-2003. Health Econ 2009; 18(5): 519-534.

17. Kerr M. Costs and benefits of antithrombotic therapy in atrial fibrillation in England: an economic analysis based on GRASP-AF. The National Archives, https://es.slideshare.net/ NHSIQ/af-economic-analysis (2014, accessed 5 December 2018).

18. Gotto AM, Boccuzzi SJ, Cook JR, et al. Effect of lovastatin on cardiovascular resource utilization and costs in the Air Force/ Texas Coronary Atherosclerosis Prevention Study (AFCAPS/ TexCAPS). Am J Cardiol 2000; 86(11): 1176-1181.

19. Cutler D, Long G, Berndt E, et al. The value of antihypertensive drugs: a perspective on medical innovation. Health Aff 2007; 26(1): 97-110. 
20. Greenberg P, Kessler R, Birnbaum H, et al. The economic burden of depression in the United States: how did it change between 1990 and 2000? J Clin Psychiatry 2003; 64(12): 1465-1475.

21. Costello CRW, Long DA, Gaine S, et al. Therapy with omalizumab for patients with severe allergic asthma improves asthma control and reduces overall healthcare costs. Ir J Med Sci 2011; 180(3): 637-641.

22. Bozzette SA, Joyce G, McCaffrey DF, et al. Expenditures for the care of HIV-infected patients in the era of highly active antiretroviral therapy. N Engl J Med 2001; 344(11): 817-823.

23. Ehreth J. The value of vaccination: a global perspective. Vaccine 2003; 21(27-30): 4105-4117.

24. Ozawa S, Clark S, Portnoy A, et al. Return on investment from childhood immunization in low- and middle-income countries, 2011-20. Health Aff 2016; 35(2): 199-207.

25. Zhou F, Shefer A, Wenger J, et al. Economic evaluation of the routine childhood immunization program in the United States, 2009. Pediatrics 2014; 133(4): 577-585.

26. Ekwueme DU, Strebel PM, Hadler SC, et al. Economic evaluation of use of diphtheria, tetanus, and acellular pertussis vaccine or diphtheria, tetanus, and whole-cell pertussis vaccine in the United States, 1997. Arch Pediatr Adolesc Med 2000; 154(8): 797-803.

27. Luyten $\mathrm{J}$ and Beutels $\mathrm{P}$. The social value of vaccination programs: beyond cost-effectiveness. Health Aff 2016; 35(2): 212-218.

28. Thompson KM and Tebbens RJD. Retrospective costeffectiveness analyses for polio vaccination in the United States. Risk Anal 2006; 26(6): 1423-1440.

29. Nichol KL, Wuorenma J and Sternberg T. Benefits of influenza vaccination for low-, intermediate-, and highrisk senior citizens. Arch Intern Med 1998; 158(16): 1769-1776.

30. Scuffham PA and West PA. Economic evaluation of strategies for the control and management of influenza in Europe. Vaccine 2002; 20(20): 2562-2578.

31. Shields GE, Elvidge J and Davies LM. A systematic review of economic evaluations of seasonal influenza vaccination for the elderly population in the European Union. BMJ Open 2017; 7(6): e014847.

32. García-Altés A. Systematic review of economic evaluation studies: are vaccination programs efficient in Spain? Vaccine 2013; 31(13): 1656-1665.

33. Mäkelä MJ, Backer V, Hedegaard M, et al. Adherence to inhaled therapies, health outcomes and costs in patients with asthma and COPD. Respir Med 2013; 107(10): 1481-1490.

34. Cutler RL, Fernandez-Llimos F, Frommer M, et al. Economic impact of medication non-adherence by disease groups: a systematic review. BMJ Open 2018; 8(1): e016982.

35. Sokol M, McGuigan K, Verbrugge R, et al. Impact of medication adherence on hospitalization risk and healthcare cost. Med Care 2005; 43(6): 521-530.

36. Stuart B, Loh F, Roberto P, et al. Increasing Medicare part $\mathrm{D}$ enrollment in medication therapy management could improve health and lower costs. Health Aff 2013; 32(7): $1212-1220$.

37. Steffens B. Cost-effective management of type 2 diabetes: providing quality care in a cost-constrained environment. Am J Manag Care 2000; 6(13 Suppl.): S697-S703.
38. Lee WC, Balu S and Cobden D. Medication adherence and the associated health-economic impact among patients with type 2 diabetes mellitus converting to insulin pen therapy: an analysis of third-party managed care claims data. Clin Ther 2006; 28(10): 1712-1725.

39. Pawaskar MD, Camacho F and Anderson R. Health care costs and medication adherence associated with initiation of insulin pen therapy in Medicaid-enrolled patients with type 2 diabetes: a retrospective database analysis. Clin Ther 2007; 29: 1294-1305.

40. Schoenmakers B, Buntinx F and Lepeleire JD. Can pharmacological treatment of behavioural disturbances in elderly patients with dementia lower the burden of their family caregiver? Fam Pract 2009; 26(4): 279-286.

41. Polistena B, Calzavara-Pinton P, Altomare G, et al. The impact of biologic therapy in chronic plaque psoriasis from a societal perspective: an analysis based on Italian actual clinical practice. J Eur Acad Dermatol Venereol 2015; 29(12): 2411-2416.

42. Tsiachristas A, Notenboom A, Goudriaan R, et al. Medical innovations and labor savings in health care. An exploratory study. Aarts De Jong Wilms Goudriaan Public Economics by (APE) and Maastricht University, https:// www.zorgvoorinnoveren.nl/uploads/media/Medical_ innovations_and_labor_savings_in_health_care.pdf (2009, accessed 5 December 2018).

43. Bui V and Stolpe M. The impact of new drug launches on the loss of labor from disease and injury: evidence from German panel data. Int J Health Care Finance Econ 2010; 10(4): 315-346.

44. Lichtenberg FR. The effect of changes in drug utilization on labor supply and per capita output. National Bureau of Economic Research. Report no. 9139, http://www.nber.org/ papers/w9139 (2002, accessed 5 December 2018).

45. Lichtenberg FR. Availability of new drugs and Americans' ability to work. J Occup Environ Med 2005; 47(4): 373 380 .

46. Huscher D, Mittendorf T, Hinüber U, et al. Evolution of cost structures in rheumatoid arthritis over the past decade. Ann Rheum Dis 2015; 74(4): 738-745.

47. Carls GS, Roebuck MC, Brennan TA, et al. Impact of medication adherence on absenteeism and short-term disability for five chronic diseases. J Occup Environ Med 2012; 54(7): 792-805.

48. Doz M, Chouaid C, Com-Ruelle L, et al. The association between asthma control, health care costs, and quality of life in France and Spain. BMC Pulm Med 2013; 13: 15.

49. Zhang $Y$ and Soumerai SB. Do newer prescription drugs pay for themselves? A reassessment of the evidence. Health Aff 2007; 26(3): 880-886.

50. Bansback N, Fu E, Sun H, et al. Do biologic therapies for rheumatoid arthritis offset treatment-related resource utilization and cost? A review of the literature and an instrumental variable analysis. Curr Rheumatol Rep 2017; 19: 54.

51. Joyce GF, Goldman DP, Karaca-Mandic P, et al. Impact of specialty drugs on use of other medical services. $\mathrm{Am} \mathrm{J}$ Manag Care 2008; 14: 821-828.

52. Karaca-Mandic P, McCullough JS, Siddiqui MA, et al. Impact of new drugs and biologics on colorectal cancer treatment and costs. J Oncol Pract 2011; 7: e30s-e37s. 
53. Liu YM and Hsieh CR. New drugs and the growth of health expenditure: evidence from diabetic patients in Taiwan. Health Econ 2012; 21(5): 496-513.

54. Miller G, Moeller J and Stafford R. New cardiovascular drugs: patterns of use and association with non-drug health expenditures. Inquiry 2005; 42(4): 397-412.

55. Briesacher BA, Madden JM, Zhang F, et al. Did Medicare part D affect national trends in health outcomes or hospitalizations? A time-series analysis. Ann Intern Med 2015; 162: 825-833.

56. Zozaya N, Martínez-Galdeano L, Alcalá B, et al. Evaluación financiación y regulación de los medicamentos innovadores en la OCDE. Weber, http://weber.org.es/wp-content/uploads
/2018/02/Informe-Evaluaci\%C3\%B3n-financiaci\%C3\%B3n-yregulaci $\% \mathrm{C} 3 \% \mathrm{~B} 3 n$-de-los-medicamentos-innovadoresen-los-pa\%C3\%ADses-desarrollados_imprimir.pdf (2017, accessed 5 December 2018).

57. Jönsson B and Steen K. The value of new medicines 2014. 1st ed. Stockholm: SNS Förlag, 2014.

58. Department of Health, Australian Government. Appendix 6 Including nonhealth outcomes in a supplementary analysis (PBAC guidelines). Department of Health, Australian Government, https://pbac.pbs.gov.au/appen dixes/appendix-6-including-nonhealth-outcomes-in-asupplementary-analysis.html (2016, accessed 5 December 2018). 